\title{
FcyRIIB is a T cell checkpoint in antitumor immunity
}

\author{
Clara R. Farley, ${ }^{1}$ Anna B. Morris, ${ }^{1}$ Marvi Tariq, ${ }^{1}$ Kelsey B. Bennion, ${ }^{1}$ Sayalee Potdar, ${ }^{1}$ \\ Ragini Kudchadkar, ${ }^{2,3}$ Michael C. Lowe, ${ }^{1,3}$ and Mandy L. Ford ${ }^{1}$ \\ 'Department of Surgery and 'Department of Hematology and Oncology, Emory University School of Medicine, Atlanta, \\ Georgia, USA. ${ }^{3}$ Winship Cancer Institute, Emory University, Atlanta, Georgia, USA.
}

\begin{abstract}
In the setting of cancer, T cells upregulate coinhibitory molecules that attenuate TCR signaling and lead to the loss of proliferative capacity and effector function. Checkpoint inhibitors currently in clinical use have dramatically improved mortality from melanoma yet are not effective in all patients, suggesting that additional pathways may contribute to suppression of tumor-specific $\mathrm{CD8}^{+} \mathrm{T}$ cell responses in melanoma. Here, we show that Fc $\gamma \mathrm{RIIB}$, an inhibitory Fc receptor previously thought to be exclusively expressed on B cells and innate immune cells, is upregulated on tumorinfiltrating effector $\mathrm{CD8}{ }^{+} \mathrm{T}$ cells in an experimental melanoma model and expressed on $\mathrm{CD8} 8^{+} \mathrm{T}$ cells in patients with melanoma. Genetic deficiency of $F c g r 2 b$ resulted in enhanced tumor-infiltrating $\mathrm{CD8}^{+} \mathrm{T}$ cell responses and significantly reduced tumor burden. Adoptive transfer experiments of $\mathrm{Fcgrab}^{-/-}$tumor antigen-specific T cells into Fc $\gamma \mathrm{RIIB}$-sufficient hosts resulted in an increased frequency of tumor-infiltrating CD8 ${ }^{+} \mathrm{T}$ cells with greater effector function. Finally, Fc $\gamma \mathrm{RIIB}$ was expressed on $\mathrm{CD}^{+}$memory $\mathrm{T}$ cells isolated from patients with melanoma. These data illuminate a cell-intrinsic role for the Fc $\gamma$ RIIB checkpoint in suppressing tumor-infiltrating CD8+ $\mathrm{T}$ cells.
\end{abstract}

Authorship note: CRF and ABM contributed equally to this work.

Conflict of interest: The authors have declared that no conflict of interest exists.

Copyright: (c) 2021, Farley et al. This is an open access article published under the terms of the Creative Commons Attribution 4.0 International License.

Submitted: December 11, 2019

Accepted: January 20, 2021

Published: February 22, 2021

Reference information: JCI Insight. 2021;6(4):e135623.

https://doi.org/10.1172/jci.

insight.135623.

\section{Introduction}

Metastatic melanoma is an aggressive form of skin cancer, with an estimated 91,270 new cases and 9320 disease-related deaths per year (1). Over the last 30 years, the incidence of melanoma has continued to rise steadily. Although patients with advanced disease (stages III and IV) have traditionally had a poor prognosis (1), recent advances in the utilization of immune-based therapies have revolutionized the management of metastatic melanoma (2). It is now well appreciated that cancer results in an increase in $\mathrm{T}$ cell expression of coinhibitory receptors, ultimately attenuating these cells' proliferative capacity and effector function (3). Recent research has shown that reinvigoration of tumor-specific $\mathrm{CD} 8^{+} \mathrm{T}$ cell responses through immune modulation is an effective strategy to reduce tumor burden and decrease mortality. In particular, treatment of patients with cancer with mAbs targeting T cell coinhibitory pathways, such as CTLA- 4 and PD-1 checkpoint inhibitors, has resulted in enhanced immune function against tumor cells and prolonged survival in patients with metastatic melanoma (4). However, not all patients are responsive to blockade of these specific checkpoint inhibitors, raising the possibility that additional novel checkpoint inhibitors exist and could be therapeutically targeted to further improve survival in patients with melanoma (5).

Fc receptors are a heterogeneous group of transmembrane immunoglobulin family molecules responsible for mediating a wide range of processes including antibody-dependent cellular cytotoxicity, endocytosis of antigen-antibody immune complexes, cytokine and chemokine production, and B cell development and homeostasis (6). Much like T cell costimulatory and coinhibitory molecules, the balance of activating and inhibitory Fc receptor signaling determines the outcome of antibody engagement of these receptors. Although there are several activating Fc receptors, Fc $\gamma$ RIIB is the only known inhibitory Fc receptor and is conserved in both mice and humans (7). It is expressed by many immune cell types including B cells, dendritic cells, macrophages, and granulocytes (8). The effect of Fc $\gamma$ RIIB inhibitory signaling on B cells has been extensively studied and reagents designed to target this inhibitory pathway are making their way into clinical trials for autoimmunity $(6,7,9,10)$. Significant work has also been done to elucidate the role of Fc $\gamma$ RIIB on B cells and other antigen-presenting cells in the setting of cancer. For example, Fc $\gamma$ RIIB on malignant B cells has been shown to accelerate internalization of targeting mAbs (e.g., the anti-CD20 mAb rituximab), hampering their ability to induce antibody-dependent cellular cytotoxicity and phagocytosis, 
and reducing their therapeutic efficacy (11). Use of an antagonistic Fc $\gamma$ RIIB antibody 6G11 has been shown to prevent this internalization and preserve the therapeutic potential of rituximab (12). In contrast, Fc $\gamma$ RIIB on B cells may potentiate the immunostimulatory effects of certain mAbs, specifically antibodies targeting CD40, OX40, and GITR, in an ITIM-independent manner by facilitating mAb cross-linking (13-16). Studies using a mouse B16 melanoma model have further demonstrated a higher efficacy of the protective IgG2a antibody TA99 in $\mathrm{F}_{\mathrm{cgr}} 2 \mathrm{~b}^{-1-}$ mice compared with WT mice (17), as demonstrated by an approximately 30 -fold greater reduction in the volume of lung metastases in $F_{c g r} 2 b^{-1-}$ mice compared with WT mice.

However, exceedingly little is known about the role of Fc $\gamma$ RIIB in directly modulating $\mathrm{T}$ cell expansion, survival, or effector function during antitumor immunity. Although early immunology literature speculated that $\mathrm{T}$ cells may express $\mathrm{Fc}$ receptors (18-20), for the past few decades the consensus has been that $\mathrm{T}$ cells do not express these molecules (6). However, several RNA-Seq data sets have suggested that Fc $\gamma$ RIIB is expressed within $\mathrm{CD}^{+} \mathrm{T}$ cell populations $(21,22)$; and although a 2014 study demonstrated protein expression by flow cytometry of Fc $\gamma$ RIIB on $\mathrm{CD}^{+} \mathrm{T}$ cells in response to microbial and viral infections (23), the functional significance of $\mathrm{F} c \gamma \mathrm{RIIB}$ on $\mathrm{CD}^{+} \mathrm{T}$ cells was unclear. We recently demonstrated a cell-autonomous role for Fc $\gamma \mathrm{RIIB}$ in regulating graft-specific $\mathrm{CD} 8^{+} \mathrm{T}$ cell responses in the context of transplantation, and during the course of those studies, we discovered that adoptive transfer of $F_{c g r} 2 b^{-1-}$ OT-I T cells into recipients of B16-OVA melanoma tumors resulted in an approximately $40 \%$ reduction in tumor volume by day 14 (24). However, the role of $\mathrm{Fc} \gamma \mathrm{RIIB}-$ expressing $\mathrm{CD} 8^{+} \mathrm{T}$ cells in modulating antigen-specific $\mathrm{CD} 8^{+} \mathrm{T}$ cell accumulation and effector function within tumors is unknown. Here, we demonstrate that Fc $\gamma$ RIIB is upregulated on a subset of activated, tumor-infiltrating $\mathrm{CD} 8^{+} \mathrm{T}$ cells and plays a cell-autonomous role in the suppression of tumor-infiltrating $\mathrm{CD}^{+} \mathrm{T}$ cells in a mouse model of melanoma. Our findings illuminate the role of a potentially novel checkpoint inhibitor in potently regulating $\mathrm{CD} 8^{+}$antitumor immunity in the setting of melanoma.

\section{Results}

Fc $\mathrm{RIIB}$ was expressed by memory $C D 8^{+} T$ cells in a murine cancer model. To determine whether Fc $\gamma \mathrm{RIIB}$ is expressed on $\mathrm{CD} 8^{+} \mathrm{T}$ cells during the immune response to melanoma, we first inoculated WT C57BL/6 (B6) mice with a B16-OVA melanoma cell line. Draining lymph node ( $\mathrm{dLN})$, spleen, and tumor were harvested on days 7, 10, and 14, respectively (Figure 1A). Fc $\gamma$ RIIB surface expression was measured using the 2.4G2 mAb.

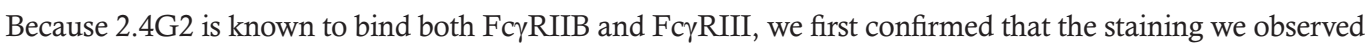
on $\mathrm{CD}^{+} \mathrm{T}$ cells was in fact specific to FcyRIIB by staining cells from both WT and $\mathrm{Fcgr}_{\mathrm{r}} 2 \mathrm{~b}^{-/-}$mice and compared the results with an isotype control. Our data demonstrated a lack of $2.4 \mathrm{G} 2$ staining on $\mathrm{Fcgr}_{2} 2 b^{-1-} \mathrm{CD} 8^{+} \mathrm{T}$ cells (Figure 1B), confirming that the staining we observed on WT CD8 $8^{+}$T cells was Fc $\gamma$ RIIB and not Fc $\gamma$ RIII expression. Interestingly, Fc $\gamma$ RIIB was not expressed on WT CD $8^{+} \mathrm{T}$ cells in the dLN, spleen, or tumor on day 7; however, Fc $\gamma$ RIIB expression was identified on a subset of CD44 ${ }^{\text {hi }} \mathrm{CD} 8^{+} \mathrm{T}$ cells in the $\mathrm{dLN}$, spleen, and tumor on days 10 and 14 (Figure 1, C and D). Importantly, Fc $\gamma$ RIIB was expressed on a significantly greater frequency of $\mathrm{CD} 44^{\mathrm{hi}} \mathrm{CD} 8^{+}$cells compared with $\mathrm{CD} 44^{\mathrm{lo}} \mathrm{CD} 8^{+}$cells (Figure 1E), indicating that Fc $\gamma$ RIIB was expressed predominantly by activated $\mathrm{CD} 8^{+} \mathrm{T}$ cells. Fc $\gamma \mathrm{RIIB}$ was also expressed on a greater frequency of $\mathrm{CD} 44^{\mathrm{hi}} \mathrm{CD} 8^{+} \mathrm{T}$ cells in the tumor and spleen compared with the draining LN (Figure 1E).

$F c \gamma R I I B$ was associated with $2 B 4$ and $P D-1$ expression on effector $C D 8^{+} T$ cells. To further explore the expression of $\mathrm{Fc} \gamma \mathrm{RIIB}$ on $\mathrm{CD}^{+} \mathrm{T}$ cells during the immune response to melanoma, we next sought to determine if there was an association between Fc $\gamma$ RIIB and other known coinhibitory receptors in melanoma. To test this, we inoculated WT B6 mice with B16-OVA melanoma cells and harvested dLN and spleen for phenotypic analysis 14 days later. $\mathrm{CD} 44^{\mathrm{hi}} \mathrm{CD} 8^{+} \mathrm{T}$ cells from the spleen and $\mathrm{dLN}$ were analyzed using viSNE (Figure 2A). As expected from our previous results (24), Fc $\gamma$ RIIB-expressing CD8 ${ }^{+} \mathrm{T}$ cells in the spleen (Figure 2B) and dLN (Figure 2C) were contained within regions of high CD44 expression. Interestingly, Fc $\gamma$ RIIB was expressed on cells in regions of both high and low CD62L expression, suggesting that Fc $\gamma$ RIIB was expressed on both central $\left(\mathrm{CD} 44^{\mathrm{hi}} \mathrm{CD} 62 \mathrm{~L}^{\mathrm{hi}}\right)$ and effector $\left(\mathrm{CD} 44^{\mathrm{hi}} \mathrm{CD} 62 \mathrm{~L}^{\mathrm{lo}}\right)$ memory $\mathrm{CD}^{+} \mathrm{T}$ cells. Moreover, viSNE analysis revealed that $\mathrm{F}_{\mathrm{C}} \gamma \mathrm{RIIB}^{+}$cells were contained within regions of high 2B4 and PD-1 expression in both the spleen (Figure 2D) and the dLN (Figure 2E). To confirm these results, we then used traditional manual gating in FlowJo to assess CD62L, 2B4, and PD-1 expression on Fc $\mathrm{RIIB}^{-}$and $\mathrm{Fc}_{\mathrm{C}} \gamma \mathrm{RIIB}^{+} \mathrm{CD} 44^{\mathrm{hi}} \mathrm{CD} 8^{+} \mathrm{T}$ cells in the $\mathrm{dLN}$ and spleen. Consistent with the viSNE analysis, we observed that $\mathrm{Fc}_{\mathrm{R}} \mathrm{RIB}^{+} \mathrm{CD} 44^{\mathrm{hi}} \mathrm{CD} 8^{+} \mathrm{T}$ cell populations in the spleen (Figure $2 \mathrm{~F}$ ) and dLN (Figure $2 \mathrm{G}$ ) contained a significantly reduced frequency of $\mathrm{CD} 62 \mathrm{~L}^{+}$cells and a significantly increased frequency of $2 \mathrm{~B} 4^{+}$and $\mathrm{PD}-1^{+}$cells relative to the $\mathrm{F} c \gamma \mathrm{RIIB}^{-} \mathrm{CD} 44^{\text {hi }} \mathrm{CD} 8^{+} \mathrm{T}$ cell populations. 
A

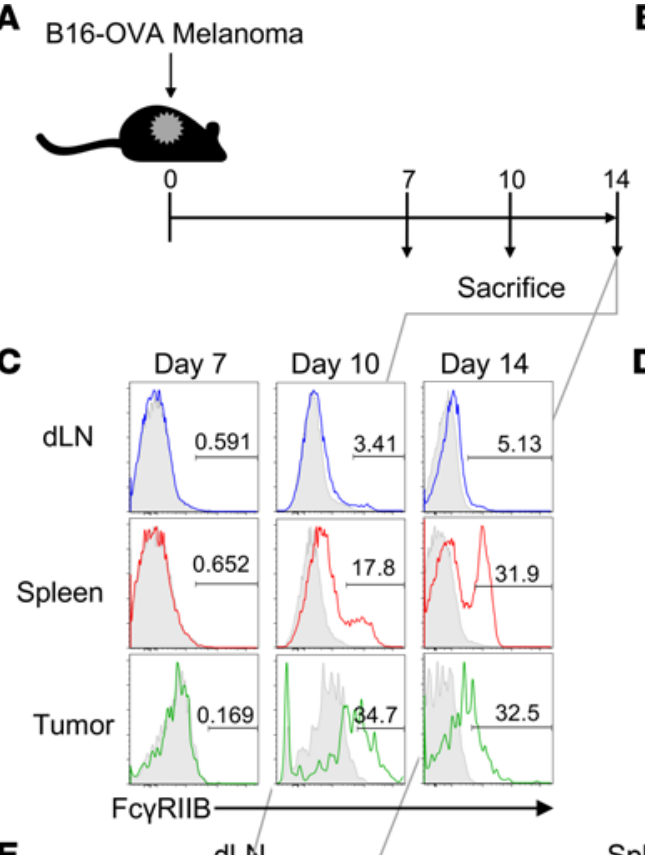

B

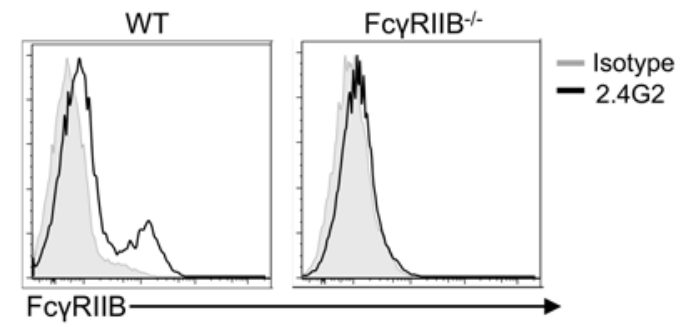

E
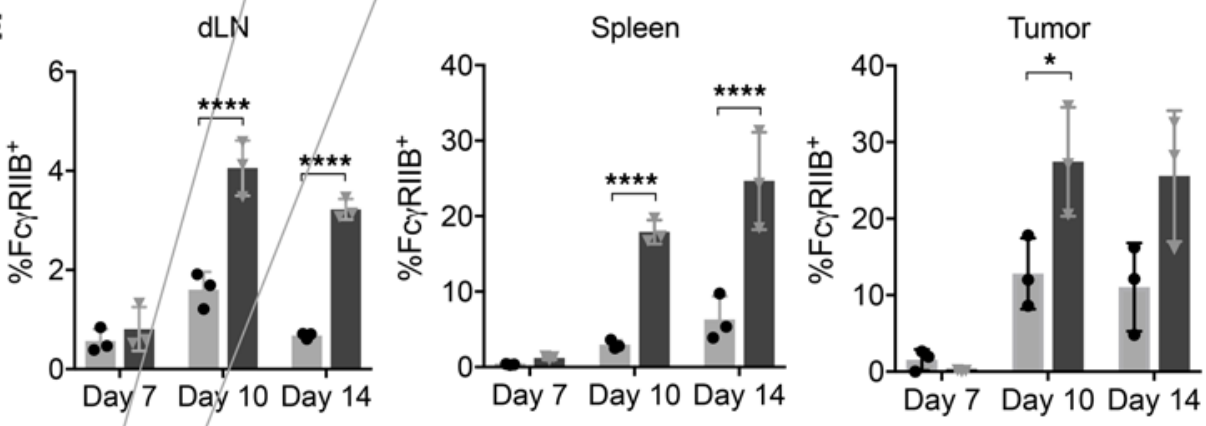

- $\mathrm{CD}_{4} 4^{10} \mathrm{CD} 8^{+}$

$\checkmark \mathrm{CD}_{4} 4^{\mathrm{hi}} \mathrm{CD} 8^{+}$

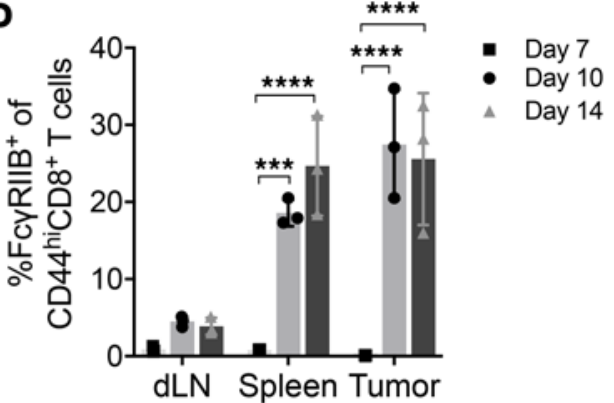

Figure 1. Fc $\gamma R$ RIIB is expressed on memory CD8 ${ }^{+}$T cells in a murine cancer model. (A) Schematic of experimental design: $10^{6}$ B16-OVA melanoma cells were injected into the subcutaneous tissue of the right flank of C57BL/ 6 mice on day 0 . Spleen, draining lymph node (dLN), and tumor were harvested on days 7, 10, and 14. (B) CD44 ${ }^{\text {hicD }}{ }^{+} T$ cells from the spleen of C57BL/6 (WT) and Fcgr2 $b^{-1-}$ mice were stained with anti-FcyRIIB/III (clone 2.4G2) (black) and isotype control (gray) on day 10 after tumor inoculation. (C) Representative histograms of FcyRIIB expression (clone 2.4G2) on CD44 ${ }^{\text {hiCD }}{ }^{+} \mathrm{T}$ cells in the dLN (blue), spleen (red), and tumor (green) on days 7, 10, and 14 after tumor inoculation. Corresponding isotype controls are shown in gray. (D) Summary data of Fc $\gamma$ RIIB expression (clone 2.4G2) on CD44hicD8 T cells in the dLN (blue), spleen (red), and tumor (green) on days 7, 10, and 14 after tumor inoculation. (E) Frequencies of Fc $\gamma$ RIIB expression on $\mathrm{CD} 44^{10} \mathrm{CD}^{+}$(black) and $\mathrm{CD} 44^{\text {hic }} \mathrm{CD}^{+}$(gray) in the $\mathrm{dLN}$, spleen, and tumor. Data shown are representative of three independent experiments; $n=3-5$ mice/group/experiment. Two-way ANOVA with multiple comparisons, ${ }^{*} P<0.05$, ${ }^{* *} P<0.0005$, ${ }^{* * *} P<0.0001$.

Fcgr2b-1- mice have improved antitumor immunity and reduced tumor volume compared with WT mice. Because these data suggested that Fc $\gamma$ RIIB expression was associated with a more activated and potentially exhausted phenotype on $\mathrm{CD}^{+} \mathrm{T}$ cells, we next queried the functional role of Fc $\gamma \mathrm{RIIB}$ during antitumor immunity. WT and $F_{c g r} 2 b^{-1-}$ mice were inoculated with B16-OVA melanoma on day 0. On day 14, tumor volume was measured, and $\mathrm{dLN}$, spleen, and tumor were harvested to assess the $\mathrm{CD} 8^{+} \mathrm{T}$ cell response to the tumor (Figure 3A). Results revealed a significant decrease in tumor volume in $F c g r 2 b^{-1-}$ animals compared with WT 
A
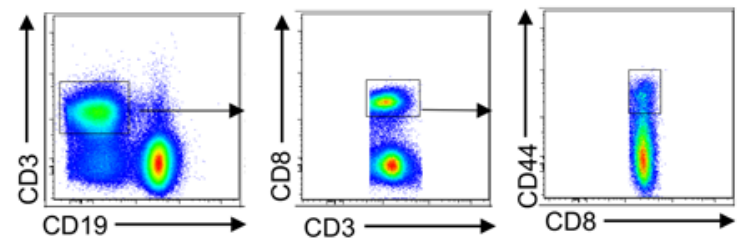

B

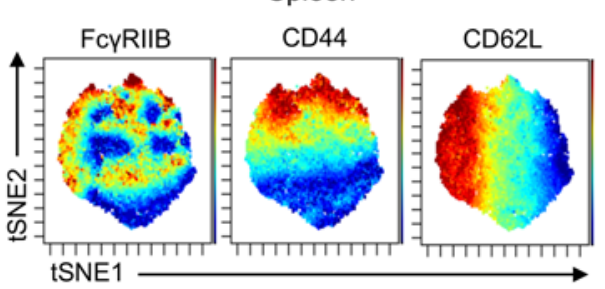

D

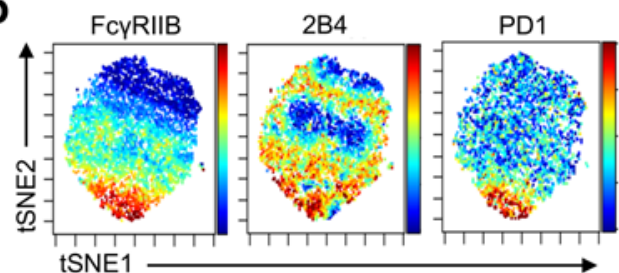

C

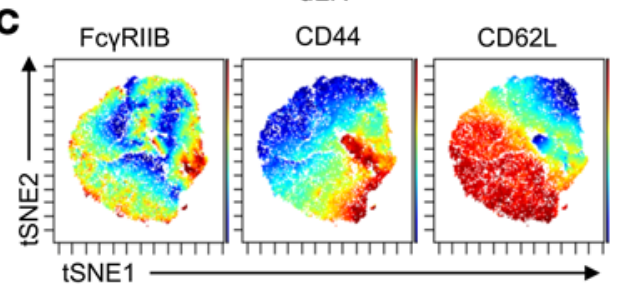

E

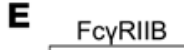

E FCYRIIB

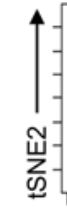

\section{G}
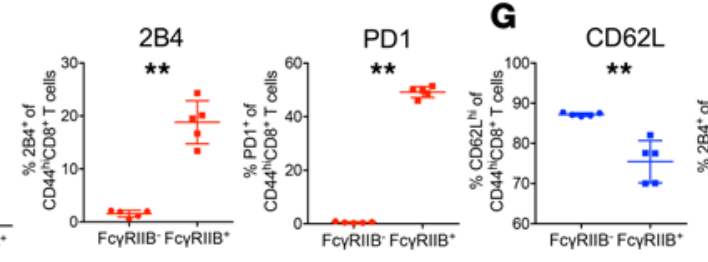

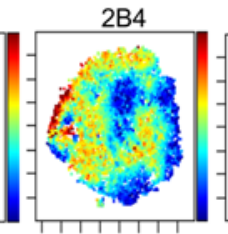

PD1
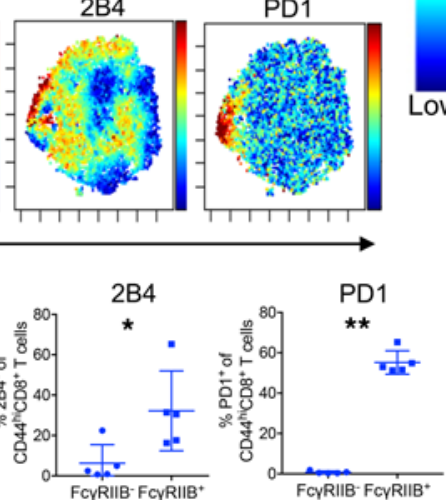

Figure 2. FcyRIIB is associated with $2 \mathrm{~B} 4$ and PD-1 expression on CD44 hicD8 ${ }^{+} \mathrm{T}$ cells in the spleen and dLN in mice with melanoma. $10^{6}$ B16-OVA melanoma cells were subcutaneously injected into the right flank of C57BL/6 mice on day 0. Spleen and dLN were harvested on day 14. (A) Using conventional fluorescence-based flow cytometry, bulk CD3+CD8 ${ }^{+}$ T cells (B and $\mathbf{C}$ ) and $\mathrm{CD} 44^{\text {hi }}{ }^{\mathrm{CD}} 8^{+} \mathrm{CD}^{+} \mathrm{T}$ cells ( $\mathbf{D}$ and $\mathbf{E}$ ) were gated and exported as FCS files for viSNE analysis. (B) viSNE maps showing the intensity of Fc $\gamma R$ IIIB, CD44, and CD62L expression on CD8 ${ }^{+}$T cells in the spleen. (C) viSNE maps showing intensity of FcyRIIB, CD44, and CD62L expression on CD8 ${ }^{+}$T cells in the dLN. (D) viSNE maps showing intensity of expression of FcyRIIB, 2B4, and PD-1 on CD44 hicD8+ $T$ cells in the spleen. (E) viSNE maps showing intensity of expression of FcyRIIB, 2B4, and PD-1 on CD44 hicD8 ${ }^{+}$T cells in the dLN. (F) Summary data of the frequency of CD62 $\mathrm{L}^{\text {hi }}$, $2 \mathrm{~B} 4^{+}$, and $\mathrm{PD} 1^{+} \mathrm{F} c \gamma \mathrm{RIIB}{ }^{+}$and Fc $\gamma \mathrm{RIIB}-\mathrm{CD} 44^{\mathrm{hi}} \mathrm{CD} 8^{+} \mathrm{T}$ cells in the spleen. (C) Summary data of the frequency of CD62 $\mathrm{L}^{\mathrm{hi}}$, $2 \mathrm{~B} 4^{+}$, and $\mathrm{PD} 1^{+} \mathrm{Fc} \gamma \mathrm{RIIB} \mathrm{B}^{+}$and $\mathrm{Fc} \gamma \mathrm{RIIB}-\mathrm{CD} 44^{\text {hi }}{ }^{\mathrm{CD}} 8^{+} \mathrm{T}$ cells in the dLN. Data shown are representative of 2 independent experiments; $n=5$ mice/group/experiment. Mann-Whitney $U$ test, ${ }^{*} P<0.05,{ }^{* *} P<0.005$. dLN, draining lymph node.

controls (Figure 3, B and C). Consistent with these results, $F c g r 2 b$ deficiency resulted in a greater frequency of tumor-infiltrating CD8 ${ }^{+} \mathrm{T}$ cells compared with WT controls (Figure 3, D and E). Moreover, tumors in $F \mathrm{cgr} 2 \mathrm{~b}^{-1-}$ animals contained a marked increase in the proportion of infiltrating memory $\left(\mathrm{CD} 44^{\mathrm{hi}} \mathrm{CD} 62 \mathrm{~L}^{+}\right.$and $\left.\mathrm{CD} 44^{\text {hi }} \mathrm{CD} 62 \mathrm{~L}^{-}\right)$subsets relative to naive $\left(\mathrm{CD} 44^{10} \mathrm{CD} 62 \mathrm{~L}^{+}\right) \mathrm{CD} 8^{+} \mathrm{T}$ cells, compared with WT animals (Figure $3 \mathrm{~F})$. In contrast, we observed no difference in $\mathrm{CD} 8^{+} \mathrm{T}$ cell frequency of memory subset distribution within the spleens of WT versus $\mathrm{Fcgr}_{\mathrm{r}} \mathrm{b}^{--}$animals (data not shown). However, spleens (but not dLN) of $\mathrm{Fcgr}_{2} \mathrm{~b}^{-1-}$ animals contained a significantly higher frequency of effector memory $\mathrm{CD} 8^{+} \mathrm{T}$ cells $\left(\mathrm{CD} 44^{\mathrm{hi}} \mathrm{CD} 62 \mathrm{~L}^{10}\right)$ compared with WT controls $(P=0.0079)$ (Figure $3 \mathrm{G})$. Importantly, the tumors of $\mathrm{Fcgr}_{2} \mathrm{~b}^{-1-}$ animals also contained higher frequencies of the effector memory $\mathrm{CD} 8^{+} \mathrm{T}$ cell subset compared with WT controls (Figure $3 \mathrm{G}$ ).

To determine the functional impact of $F c g r 2 b$ deficiency on $\mathrm{CD}^{+} \mathrm{T}$ cell responses in melanoma, the production of inflammatory cytokines by $\mathrm{CD} 8^{+} \mathrm{T}$ cells was assessed after ex vivo stimulation with PMA/ ionomycin. Results demonstrated a significantly increased frequency of IFN- $\gamma^{+} \mathrm{TNF}^{+}$double cytokine producers within the $\mathrm{CD} 8^{+} \mathrm{T}$ cell populations of the $\mathrm{dLN}$, spleen, and, importantly, within the tumors of Fcgr2b $b^{-1-}$ animals compared with WT controls (Figure 3, H and I).

FcyRIIB inhibited tumor-specific $C D 8^{+}$TIL responses in a cell-autonomous manner. Because FcyRIIB is a known inhibitory receptor on innate immune cells and B cells, the results described above could be due to either a 
A

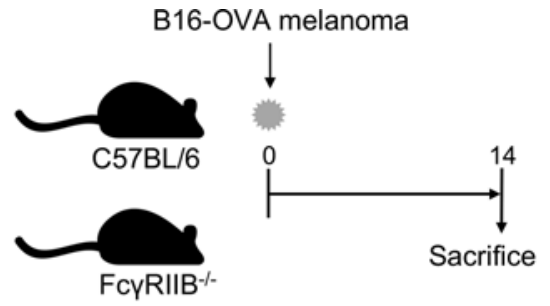

B

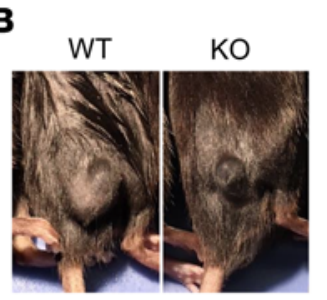

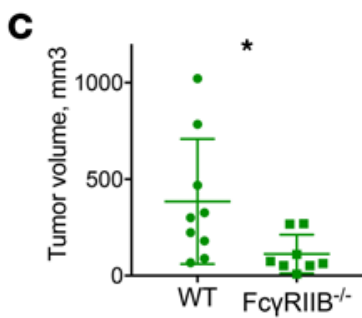

D

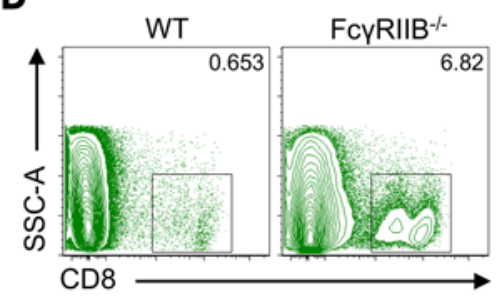

E

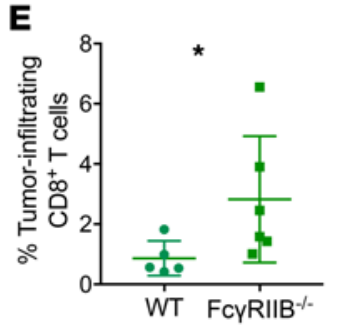

$\mathbf{F}$

Tumor-infiltrating

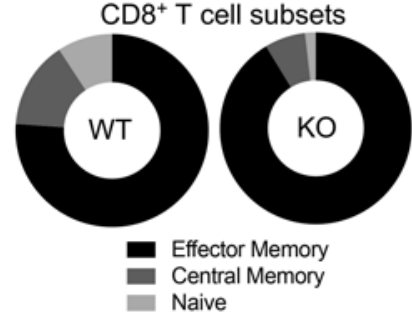

G
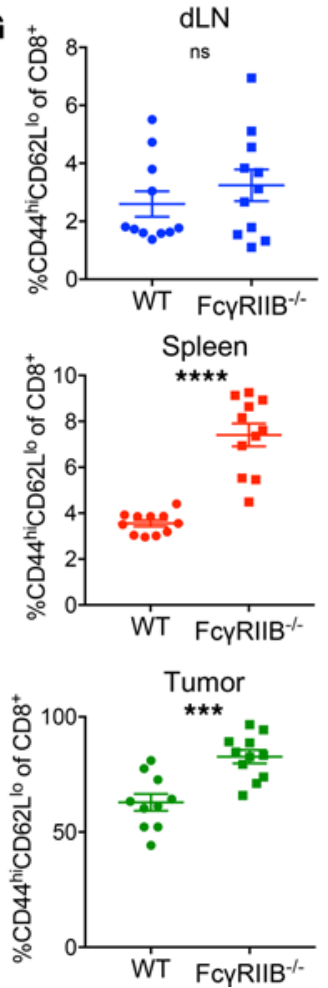

H
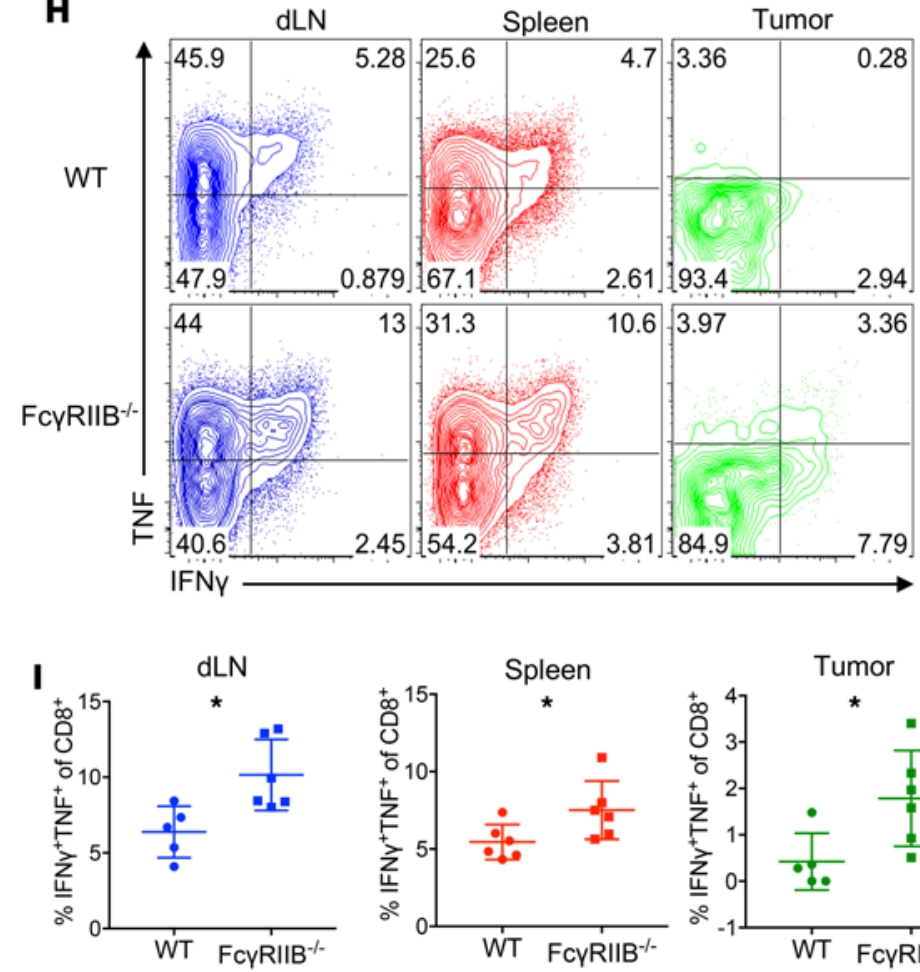

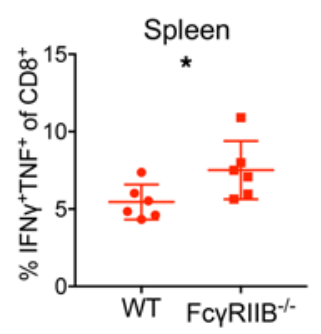

Figure 3. $\mathbf{F} \mathbf{c g r} \mathbf{2} \mathbf{b}^{-/-}$mice have an improved antitumor response compared with WT mice. (A) Schematic of experimental design: $10^{6}$ B16-OVA melanoma cells were subcutaneously injected into the right flank of C57BL/6 (WT) and Fcgr2b-1mice on day 0 . Spleen, dLN, and tumor were harvested on day 14. (B) Representative pictures of tumor growth in WT and Fcgr2 $b^{-1-}$ mice. (C) Tumor volume in WT and Fcgr2b-1-mice. (D) Representative flow cytometry plots of tumor-infiltrating $\mathrm{CD}^{+} \mathrm{T}$ cells in WT and $\mathrm{Fcgr2b^{-1- }}$ mice. (E) Summary data of CD8 $8^{+} \mathrm{T}$ cells within the tumor of WT and Fcgr2 $\mathrm{b}^{-1-}$ mice. (F) Differences in $\mathrm{CD} 44^{\mathrm{l}} \mathrm{CD} 62 \mathrm{~L}^{\mathrm{hi}}$ (naive), $\mathrm{CD} 44^{\mathrm{hi}} \mathrm{CD} 62 \mathrm{~L}^{\mathrm{hi}}$ (central memory), and $\mathrm{CD} 44^{\mathrm{hi}} \mathrm{CD} 62 \mathrm{~L}^{\mathrm{lo}}$ (effector memory) $\mathrm{T}$ cell populations in the tumor of WT Fcgr2 $\mathrm{b}^{-1-}$ (KO) mice, represented in mean. (C) Summary data of the frequency of CD44 ${ }^{\text {hi }} \mathrm{CD} 2 \mathrm{~L}^{10}$ cells of the CD8+ T cell population in the dLN, spleen, and tumor. (H) Representative flow plots of CD8 ${ }^{+}$double cytokine producers (IFN- $\left.\gamma^{+} \mathrm{TNF}^{+}\right)$in the dLN, spleen, and tumor of WT and $\mathrm{Fcgr}_{2 \mathrm{~b}^{-/-}}$mice. (I) Summary data of double cytokine producers (IFN- $\gamma^{+} \mathrm{TNF}^{+}$) in the dLN, spleen, and tumor as shown in $\mathbf{H}$. Data shown are representative of 2 independent experiments; $n=4-6$ mice/group/experiment. Mann-Whitney $U$ test, ${ }^{*} P<0.05$, ${ }^{* *} P<0.001$, ${ }^{* * *} P<0.0001$. dLN, draining lymph node.

cell-autonomous effect of FcyRIIB inhibitory signals directly on $\mathrm{CD} 8^{+} \mathrm{T}$ cells or an indirect effect of Fc $\gamma \mathrm{RIIB}$ on APC or B cell populations that impact the $\mathrm{CD} 8^{+} \mathrm{T}$ cell response. Because the cell-autonomous ability of FcyRIIB to regulate tumor-infiltrating $\mathrm{CD}^{+} \mathrm{T}$ cell responses has never been tested, we generated TCRtransgenic, antigen-specific OT-I T cells that were deficient in Fcgr2b. Thy1.1+ WT or Fcgr2b $b^{-1-}$ OT-I T cells 
were adoptively transferred into naive $\mathrm{CD} 45.1^{+}$congenic recipients 24 hours prior to inoculation with B16OVA melanoma cells (Figure 4A). Mice were sacrificed 10 and 14 days later and the expression of PD-1 and Fc $\gamma$ RIIB was assessed on the WT OT-I T cells in the dLN, spleen, and tumor after a stringent gating strategy (Figure 4B). Results indicated that the spleen had the highest proportion of PD- $1^{10} \mathrm{Fc} \gamma \mathrm{RIIB}{ }^{+} \mathrm{OT}-\mathrm{I}$ T cells compared with the dLN on day 10 and the tumor on days 10 and 14 (Figure 4, C and D). Due to the high expression of PD-1 on tumor-infiltrating CD8 ${ }^{+} \mathrm{T}$ cells, we further evaluated the frequency of PD- $1^{+} \mathrm{F} c \gamma \mathrm{RIIB}{ }^{+} \mathrm{OT}-\mathrm{I} \mathrm{T}$ cells in the dLN, spleen, and tumor. We found that the proportion of PD- $1^{+} \mathrm{F} c \gamma \mathrm{RIIB}{ }^{+} \mathrm{OT}-\mathrm{I}$ T cells was substantially increased in the tumor on days 10 and 14 compared with the spleen and dLN (Figure 4, C and E). These data suggest that although both the spleen and the tumor had higher frequencies of $\mathrm{Fc}_{\mathrm{RIIB}} \mathrm{CD}^{+} \mathrm{T}$ cells compared with the $\mathrm{dLN}$, the $\mathrm{Fc} \gamma \mathrm{RIIB}^{+} \mathrm{CD} 8^{+} \mathrm{T}$ cells in the spleen were PD- ${ }^{10}$, whereas those in the tumor were $\mathrm{PD}-1^{+}$. Furthermore, analysis of the tumor-infiltrating lymphocytes on day 14 revealed that $\mathrm{Fcgr}_{\mathrm{C}} 2 b^{-1-} \mathrm{CD} 8^{+}$ CD 45.2 $2^{+}$OT-I T cells were present at significantly increased frequencies within the tumor relative to WT OT-I control cells (Figure 4, F and G). Additionally, upon ex vivo restimulation with cognate antigen, we found that

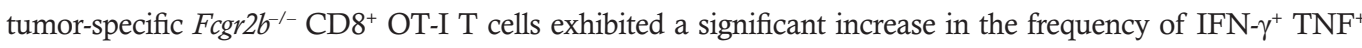
double cytokine producers in both the dLN (Figure 4, H and I) and the spleen (Figure 4, J and K) on day 10. Consistent with many previous studies $(25,26)$, cytokine production by tumor-infiltrating $\mathrm{CD}^{+} \mathrm{T}$ cells was reduced compared with $\mathrm{CD} 8^{+} \mathrm{T}$ cells within the spleen and dLN. TNF secretion was undetectable in both WT and $\mathrm{Fcgr}_{2 b^{-1-}} \mathrm{CD}^{+} \mathrm{T}$ cells (data not shown). Importantly, although IFN- $\gamma$ production was undetectable in WT tumor-infiltrating $\mathrm{CD}^{+} \mathrm{T}$ cells (Figure $4, \mathrm{~L}$ and $\mathrm{M}$ ), $\mathrm{Fcgr}_{2 b^{-1-}} \mathrm{T}$ cells contained a high frequency (approximately $7 \%$ ) of IFN- $\gamma$-producing effector $\mathrm{CD}^{+} \mathrm{T}$ cells on day 10 after tumor inoculation (Figure 4 , L and M).

Because the above-mentioned data were obtained after adoptive transfer of WT or Fcgr $2 b^{-1-}$ OT-I T cells into WT hosts, to rule out the effect of any $F c g r 2 b^{-1}$ non-T cells on the observed effects, we performed a coadoptive transfer experiment in which purified Thy $1.1^{+}$WT OT-I T cells were coadoptive transferred at a

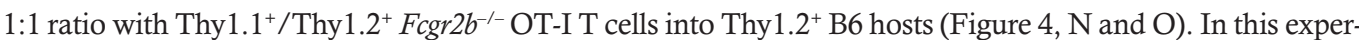
iment, WT and Fcgr2b-/- OT-I T cells were responding in the same environment, and thus any differential response could not be attributed to differential environments. As shown in Figure 4P, statistically significantly increased numbers of Thy $1.1^{+} /$Thy $1.2^{+} \mathrm{Fcgr}_{2 \mathrm{~b}^{-/}}$OT-I T cells were identified in the spleens of coadoptive transfer hosts on day 14 after tumor inoculation compared with Thy1.2+ WT OT-I T cells. These results further support the conclusion that Fc $\gamma$ RIIB functions in a cell-autonomous manner to inhibit tumor-specific $\mathrm{CD}^{+} \mathrm{T}$ cell responses in the context of tumor challenge.

$F_{c \gamma}$ RIIB was expressed on human $C D 8^{+} T$ cells isolated from patients with metastatic melanoma. Finally, we sought to determine if $\mathrm{Fc} \gamma \mathrm{RIIB}$ was expressed on $\mathrm{CD} 8^{+} \mathrm{T}$ cells in healthy human subjects and patients with melanoma. We acquired whole blood from healthy donors and from treatment-naive patients with metastatic stage III and stage IV melanoma (see Methods for patient characteristics) and isolated PBMCs for phenotypic analysis via flow cytometry. Using an anti-human CD32 mAb and fluorescence-minus-one (FMO) control, we were able to detect $\mathrm{Fc} \gamma \mathrm{RII}$ on human $\mathrm{CD}^{+} \mathrm{T}$ cells isolated from both healthy controls and patients with melanoma (Figure 5A). Although this antibody is cross-reactive for both Fc $\gamma$ RIIB and Fc $\gamma$ RIIA, we recently demonstrated that $\mathrm{CD}^{+} \mathrm{T}$ cells isolated from transplant patients contain FCGR2B mRNA (24), leading us to conclude that Fc $\gamma$ RII staining detected here was likely Fc $\gamma$ RIIB expression and not Fc $\gamma$ RIIA. The frequency of FcyRIIB-expressing CD8 ${ }^{+} \mathrm{T}$ cells was not different in the blood of healthy controls compared with patients with melanoma (Figure 5B). We next interrogated the activation status of FcyRIIB-expressing human $\mathrm{CD}^{+} \mathrm{T}$ cells. Fc $\gamma$ RIIB expression on $\mathrm{CD}^{+} \mathrm{T}$ cells isolated from healthy humans was significantly higher on effector memory expressing CD45RA T cells (Temra; CD45RA ${ }^{+}$CCR7-) relative to naive $\mathrm{T}$ cells

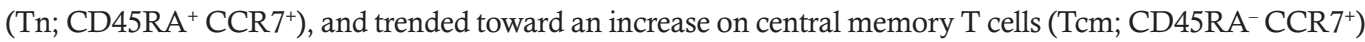
and effector memory T cells (Tem; CD45RA-CCR7 ${ }^{-}$) relative to naive T cells (Figure 5, C and D). Similar to our mouse data, we found that Fc $\gamma$ RIIB was enriched on effector/memory $\mathrm{T}$ cell populations compared with naive $\mathrm{T}$ cells in healthy human subjects. In patients with melanoma, the frequency of $\mathrm{Fc}_{\mathrm{RIIB}} \mathrm{R}^{+}$cells was similar across $\mathrm{CD}^{+} \mathrm{T}$ cell subsets (Figure 5, E and F). In comparing healthy subjects to patients with melanoma, patients with melanoma exhibited similar frequencies of all $\mathrm{T}$ cell subsets compared with healthy control subjects (Figure 5G). Of note, frequencies of $\mathrm{Fc} \gamma \mathrm{RIIB}^{+} \mathrm{CD}^{+} \mathrm{T}$ cells were decreased within the Tcm subset in patients with melanoma relative to healthy controls and trended toward a decrease in the Tem and Temra subsets in patients with melanoma relative to healthy controls $(P=0.06)$ (Figure $5 \mathrm{H})$. In sum, these data demonstrate that Fc $\gamma$ RIIB was expressed and likely played a potentially inhibitory role, on $\mathrm{CD}^{+} \mathrm{T}$ cell subsets within healthy human subjects and patients with metastatic melanoma. 

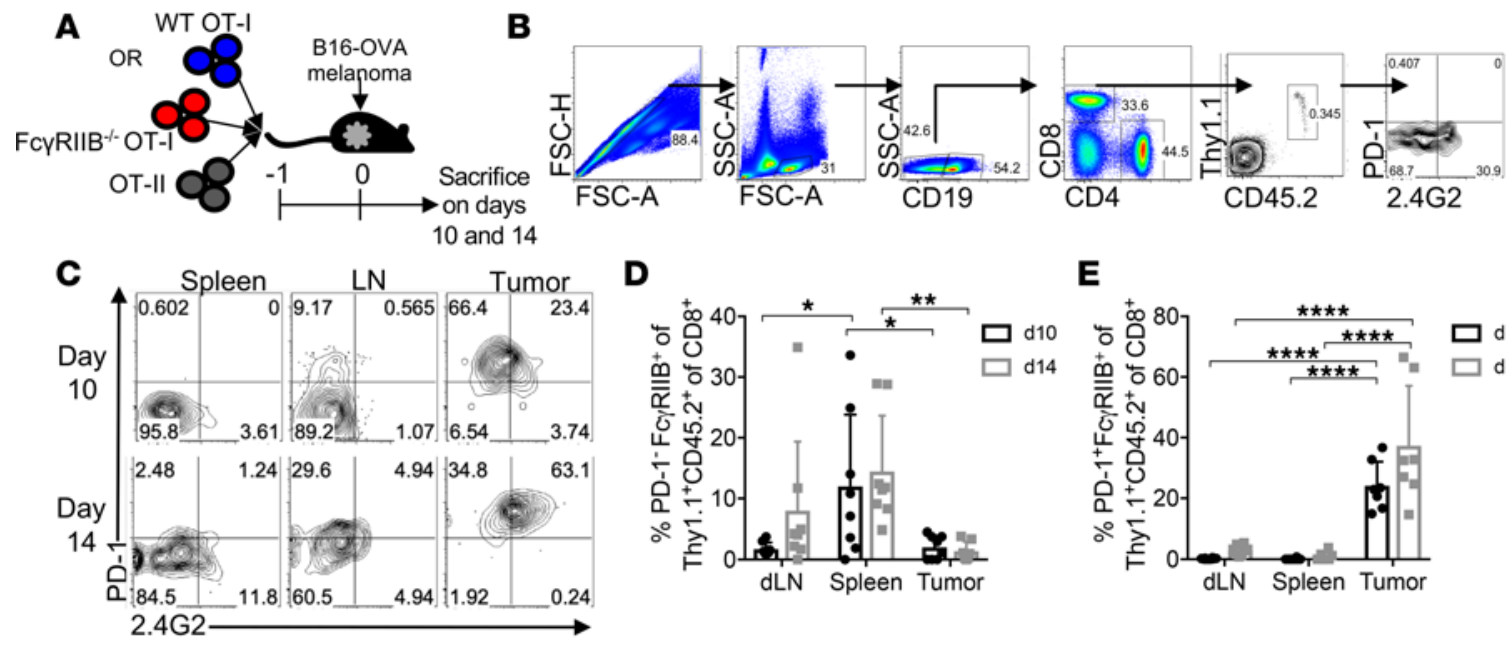

D
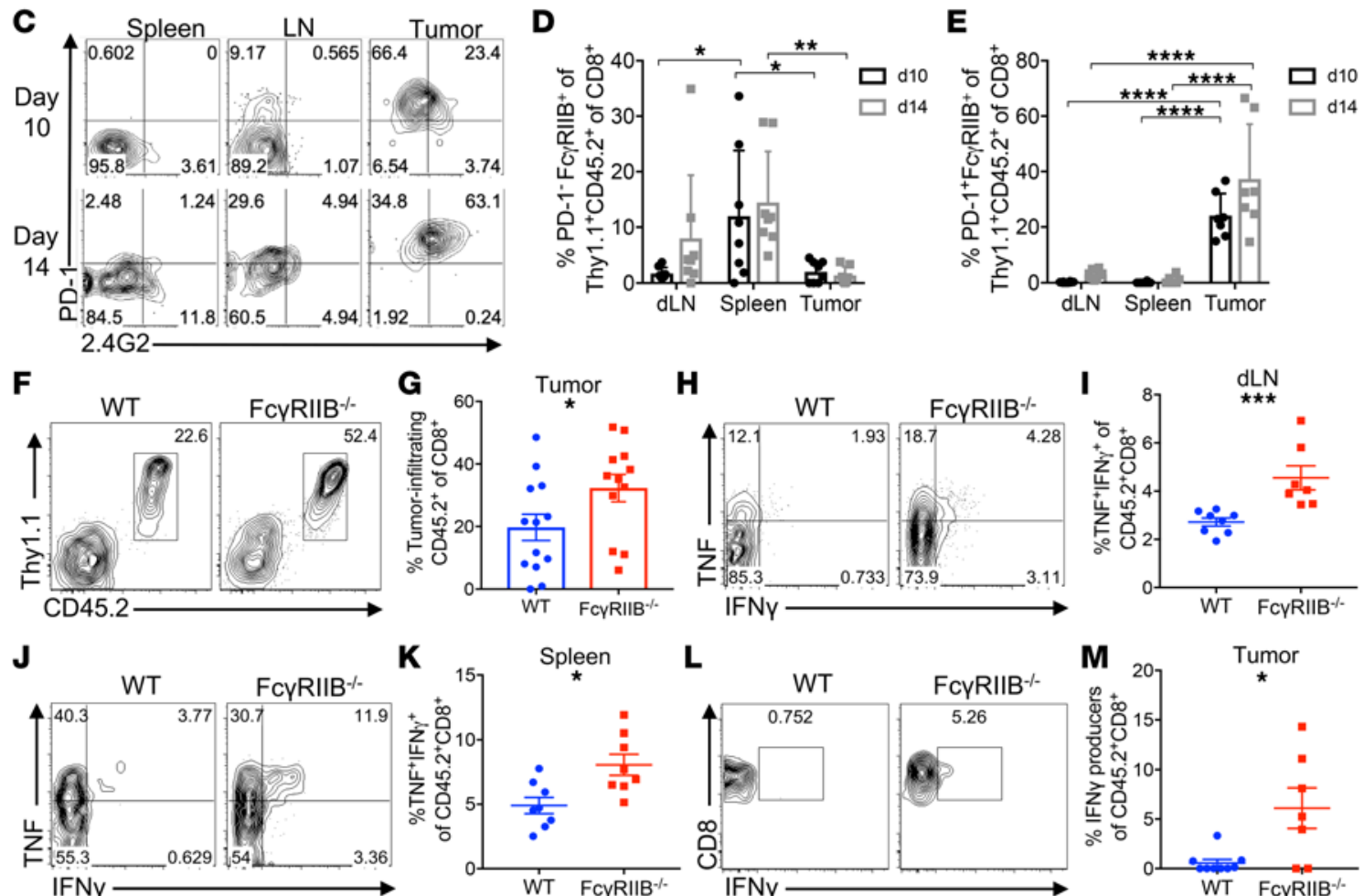

$\mathbf{L}$
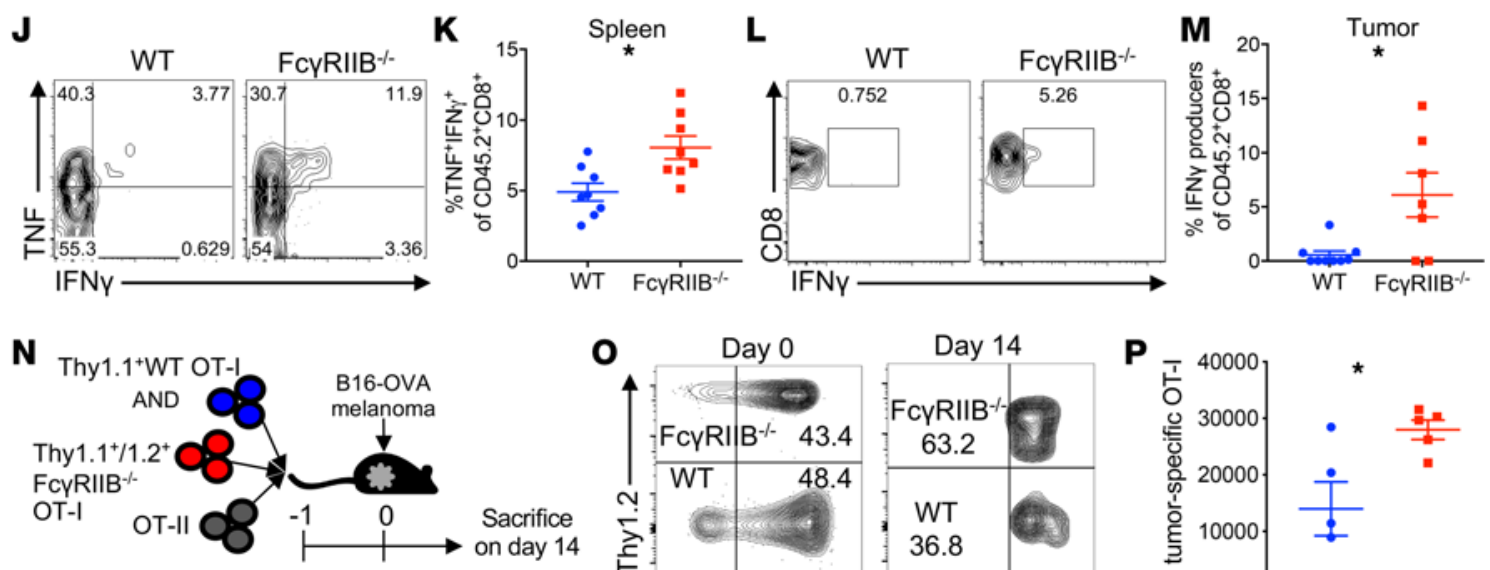

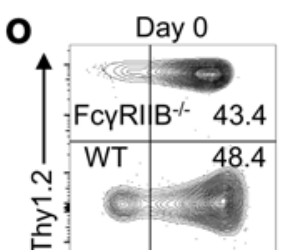

Thy 1.1
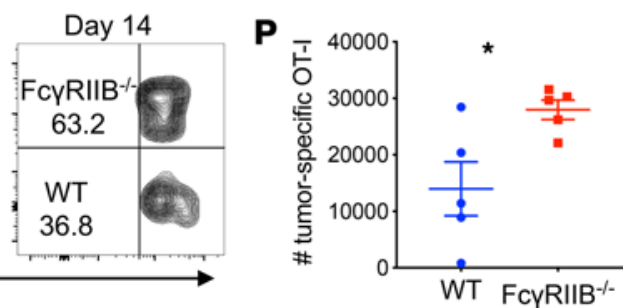

Figure 4. Specific deletion of FcyRIIB on CD8+ $T$ cells results in increased tumor infiltration and cytokine production during melanoma. (A) Experimental design: $10^{6}$ WT or Fcgr $2 b^{-1-}$ OT-I and OT-II cells were adoptively transferred into CD45.1+ mice. One day later, 10 $0^{6}$ B16-OVA cells were subcutaneously injected into the right flank. The dLN, spleen, and tumor were harvested on days 10 and 14. (B) Gating strategy for analysis of PD-1 and FC $\gamma$ RIIB on OT-I T cells. (C) Representative flow plots of PD-1 and FcyRIIB expression on WT OT-I T cells on days 10 and 14 in the spleen, dLN, and tumor. Frequencies of PD-1- (D) and PD-1 ${ }^{+}$(E) Fc RIIIB $^{+}$ OT-I CD8 ${ }^{+}$T cells on days 10 and 14. Representative flow plots (F) and summary data (C) of tumor-infiltrating WT and Fcgr2b $b^{-/-}$OT-I cells on day 14 . Representative flow plots (H) and summary data (I) of TNF and IFN- $\gamma^{+}$cells among WT and Fcgr2 $\mathrm{b}^{-/-}$OT-I cells in the dLN on day 10. Representative flow plots (J) and summary data (K) of TNF and IFN- $\gamma^{+}$cells among WT and Fcgr $2 b^{-1-}$ OT-I cells in the spleen on day 10. Representative flow plots (L) and summary data (M) of IFN- $\gamma^{+}$ cells among WT and Fcgr2 $b^{-1-}$ OT-I cells in the tumor on day 10. Data shown are representative of 2 independent experiments; $n=3-5$ mice/group/experiment. Two-way ANOVA with multiple comparisons was used in $\mathbf{D}$ and $\mathbf{E}$. Mann-Whitney $U$ tests were used in $\mathbf{G}, \mathbf{I}$, $\mathbf{K}$, and $\mathbf{M}$. (N-P) $10^{6}$ MACS-purified (>95\% CD8 ${ }^{+}$) Thy $1.1^{+}$WT or Thy $1.1^{+} /$Thy $1.2^{+}$Fcgr2 $b^{-/-}$OT-I cells and $10^{6}$ WT OT-II cells were transferred into C57BL/6 mice. One day later, 10 B16-OVA cells were subcutaneously injected. Spleens were harvested on day 14. Representative flow plots $(\mathbf{0})$ of frequencies and $(\mathbf{P})$ absolute numbers of Thy $1.1^{+}$WT vs. Fc $\gamma R$ IIIB ${ }^{-/-}$Thy $1.1^{+} /$Thy $^{1.2^{+}}$ $\mathrm{CD}^{+} \mathrm{CD}_{4}{ }^{\text {hi }}$ T cells. Mann-Whitney $U$ test was used in $\mathbf{P} .{ }^{*} P<0.05$, ${ }^{* *} P<0.01,{ }^{* * *} P<0.001,{ }^{* * * *} P<0.0001$. dLN, draining lymph node.

\section{Discussion}

Here, we report a cell-intrinsic role of Fc $\gamma$ RIIB on tumor-infiltrating $C D 8^{+} \mathrm{T}$ cells in a mouse model of melanoma. Although the effect of FcyRIIB inhibitory signaling on B cells is well studied, existing dogma has held that Fc $\gamma$ RIIB is not expressed on T cells. Here, we report that Fc $\gamma$ RIIB was expressed on approximately $30 \%$ of $\mathrm{CD} 44^{\text {hi }} \mathrm{CD} 8^{+}$tumor-infiltrating $\mathrm{CD} 8^{+} \mathrm{T}$ cells. Importantly, using an adoptive transfer approach, we were able to determine that $\mathrm{F} c \gamma \mathrm{RIIB}$ played a $\mathrm{T}$ cell-autonomous role in regulating $\mathrm{CD} 8^{+} \mathrm{T}$ cell accumulation 

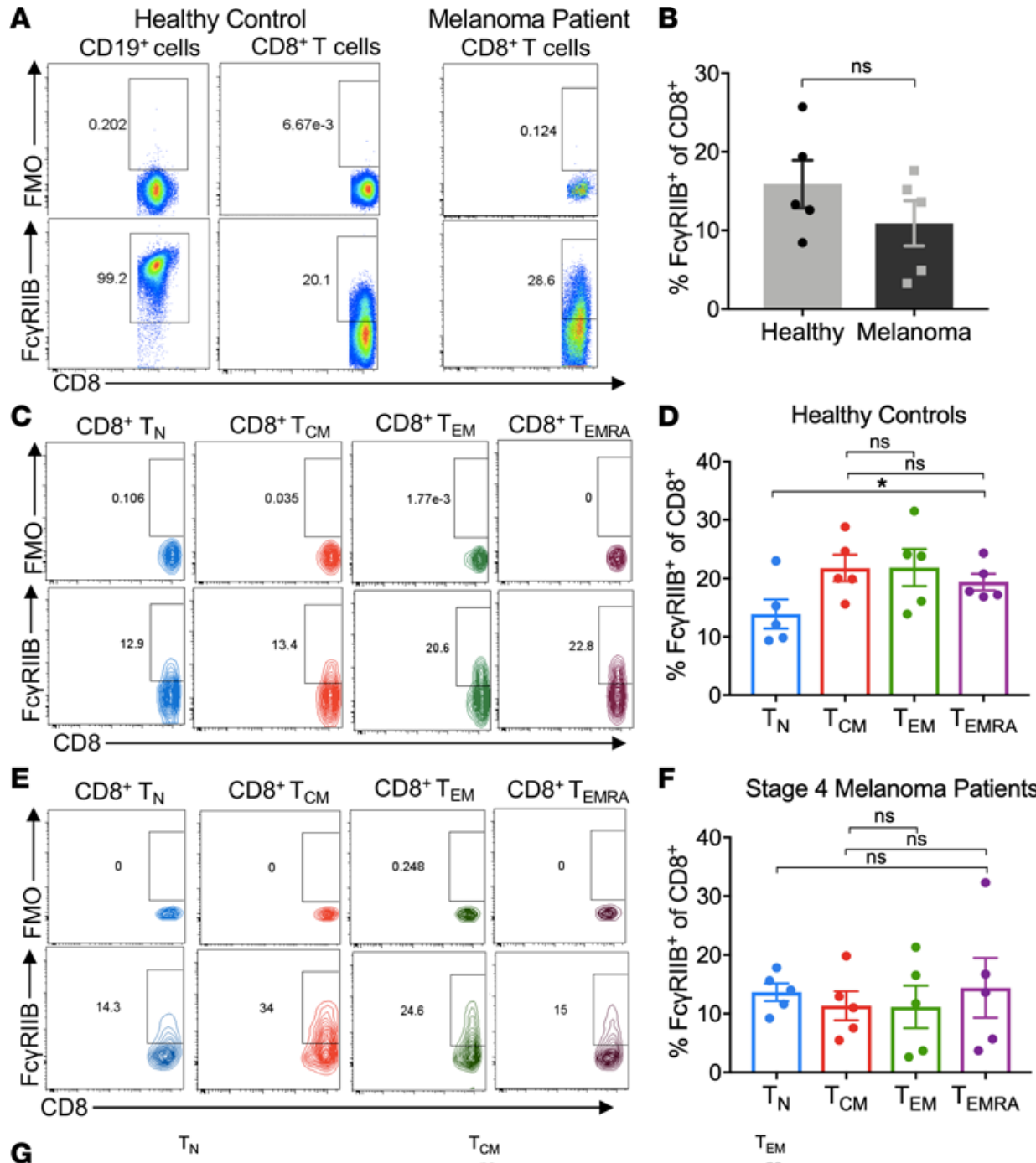

F Stage 4 Melanoma Patients
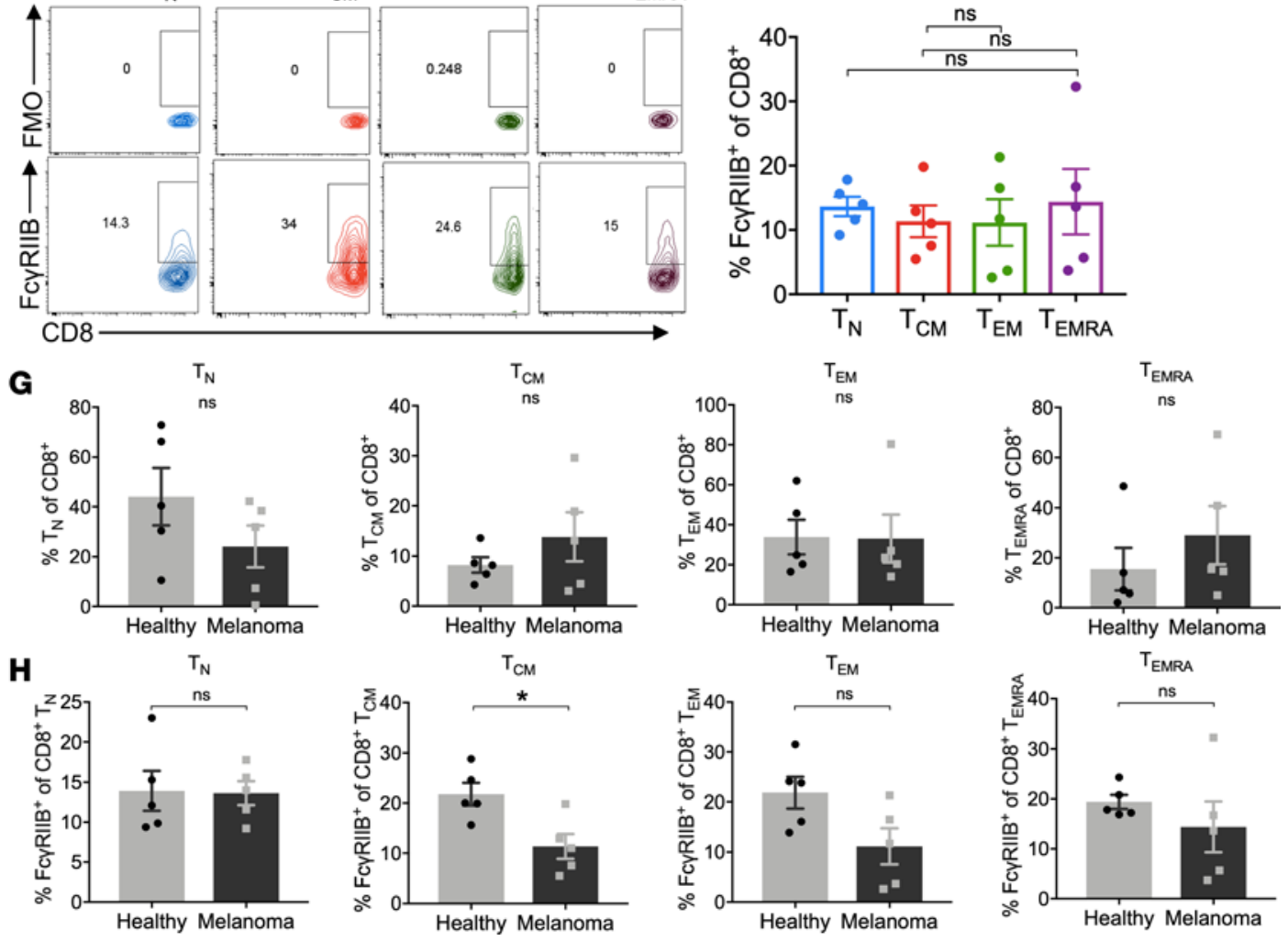

Figure 5. Human CD8 ${ }^{+}$T cells express FcyRIIB. PBMCs were obtained from healthy subjects or patients with stage IV melanoma after informed consent and analyzed directly ex vivo. (A) Representative flow plots of FcyRIIB expression (clone FLI8.26) on CD3+CD8 ${ }^{+}$T cells compared with FMO and CD19+ B cells (positive control). Gating strategy for Fc $\gamma R$ IIIB comprises gating on singlets, lymphocytes, and live CD3+ T cells while excluding CD14+, CD19+, and dead cells. (B) Summary of the frequency of $\mathrm{Fc} \gamma \mathrm{RIIB}{ }^{+} \mathrm{CD} 8^{+} \mathrm{T}$ cells in healthy subjects and patients with melanoma. (C) Representative flow plots showing FcyRIIB expression across the following $\mathrm{CD}^{+} \mathrm{CD}^{+} \mathrm{T}$ cells subsets in healthy donors: naive ( $\mathrm{Tn}$ ), central memory (Tcm), effector memory (Tem), and effector memory expressing CD45RA (Temra). (D) Summary of the frequency of FcyRIIB+ $\mathrm{CD}^{+} \mathrm{T}$ cells across the $\mathrm{Tn}, \mathrm{Tcm}$, Tem, and Temra subsets in healthy donors. (E) Representative flow plots showing FcyRIIB expression across the Tn, Tcm, Tem, and Temra $\mathrm{CD}^{+} \mathrm{CD}^{+} \mathrm{T}$ cell subsets in stage 4 treatment-naive patients with melanoma. (F) Summary of the frequency of FcyRIIB+ cells across the Tn, Tcm, Tem, and Temra CD3+CD8 ${ }^{+} \mathrm{T}$ cell subsets in patients with melanoma. (C) Summary of the frequency of the $\mathrm{Tn}, \mathrm{Tcm}$, Tem, and Temra CD3+CD8 ${ }^{+}$T cells subsets in healthy donors and patients with melanoma. (H) Summary of the frequency of FcyRIIB expression of the 
$\mathrm{Tn}, \mathrm{Tcm}$, Tem, and Temra $\mathrm{CD}^{+} \mathrm{CD} 8^{+} \mathrm{T}$ cell subsets in healthy donors and patients with melanoma. Data are representative of one experiment with $n=5$ people per group. One-way ANOVA with multiple comparisons was used to compare more than 2 groups; Mann-Whitney $U$ nonparametric, unpaired test was used to compare 2 groups. Error bar denotes mean \pm SEM. ${ }^{*} P<0.05$. FMO, fluorescence minus one.

within tumors and regulating $\mathrm{CD} 8^{+} \mathrm{T}$ cell effector function in the context of melanoma. Moreover, this study provides evidence that $\mathrm{CD} 8^{+} \mathrm{T}$ cells in patients with melanoma express $\mathrm{F} c \gamma \mathrm{RIIB}$, supporting the notion that this $\mathrm{T}$ cell inhibitory pathway could be at play in regulating antitumor responses in humans.

This work is consistent with a previous report demonstrating surface expression of Fc $\gamma$ RIIB on CD8 ${ }^{+} \mathrm{T}$ cells in models of bacterial and viral infection (23). Moreover, 2 recent studies examining the gene expression profile of virus-specific $\mathrm{CD}^{+} \mathrm{T}$ cells identified $F_{c g r} 2 b$ as being a differentially expressed gene $(21,22)$, showing that the $F c g r 2 b$ transcript is produced by CD8 ${ }^{+} \mathrm{T}$ cells (and not solely obtained by trogocytosis of Fc $\gamma$ RIIB protein from other cell types). However, whether there was a cell-autonomous functional role of Fc $\gamma$ RIIB on tumor-infiltrating $\mathrm{CD}^{+} \mathrm{T}$ cells had not been demonstrated. In light of previous data that demonstrated ectopic expression of Fc $\gamma$ RIIB on human melanoma cells but found no signaling function of the receptor, it is not a forgone conclusion that Fc $\gamma$ RIIB does influence tumor infiltration through $\mathrm{CD} 8^{+} \mathrm{T}$ cell-autonomous inhibitory signaling (27). This study by Sautes-Fridman et al. examined 259 primary and 187 metastatic lesions from 12 different cancer types and noted the selective expression of Fc $\gamma$ RIIB by metastatic melanoma cells. They hypothesized that melanoma metastases acquire expression of the inhibitory Fc $\gamma$ RIIB as a decoy receptor to serve as a sink for IgG, as a means to escape Fc $\gamma$ R-mediated lysis by antitumor IgG antibodies. However, our work demonstrates that on $\mathrm{CD}^{+} \mathrm{T}$ cells within the tumor, Fc $\gamma$ RIB had a functional, inhibitory role in suppressing $\mathrm{CD} 8^{+}$antitumor immunity.

This work contradicts a long-held dogma that $\mathrm{T}$ cells do not express $\mathrm{Fc}$ receptors. It is true that the expression level (MFI) of FcyRIIB on $\mathrm{CD}^{+} \mathrm{T}$ cells in both mice and humans is substantially lower than that observed in B cells. We speculate that this weak expression may be one reason that Fc $\gamma$ RIIB expression on $\mathrm{CD}^{+} \mathrm{T}$ cells was not initially appreciated. There are still many unanswered questions regarding the physiologic role for Fc $\gamma$ RIIB on $\mathrm{CD}^{+} \mathrm{T}$ cells, and we speculate that the differential Fc $\gamma$ RIIB expression on $B$ versus T cells may suggest ligation by distinct ligands. Although the best-known ligand for Fc $\gamma$ RIB is the Fc portion of IgG, we recently showed that the immunosuppressive cytokine Fgl2 is an alternate ligand for Fc $\gamma$ RIIB on $\mathrm{CD}^{+} \mathrm{T}$ cells (24). In addition, other studies have shown that the acute phase proteins C-reactive protein and serum amyloid protein can also bind to Fc $\gamma$ RIIB. The relative roles of each of these ligands in signaling through Fc $\gamma$ RIIB on tumor-infiltrating $\mathrm{CD}^{+} \mathrm{T}$ cells in the context of melanoma remain to be determined. Moreover, although FcyRIIB ligation has been shown to result in apoptosis in B cells, potentially through a SHIP-dependent mechanism (7), the precise mechanisms by which Fc $\gamma$ RIIB signaling results in caspase-3/7 activation in $\mathrm{T}$ cells is an important outstanding question.

Our data illuminate the role of a checkpoint inhibitor, Fc $\gamma \mathrm{RIIB}$, on $\mathrm{CD} 8^{+} \mathrm{T}$ cells in an experimental melanoma model. It is important to note that this tumor model may or may not be representative of other melanoma tumors in mice and/or humans, or of other tumor types, and further studies using additional cancer models are certainly warranted. Ongoing investigation may give rise to innovative strategies in melanoma treatment by targeting the Fc $\gamma$ RIIB pathway alone or in conjunction with other coinhibitory pathways. Indeed, because we observed an increase in PD-1 expression on Fc $\gamma \mathrm{RIIB}^{+}$cells in the tumor, it is interesting to speculate that ligation of Fc $\gamma$ RIIB by anti-PD-1 checkpoint inhibitors (28) could be sending an inhibitory signal to antitumor $\mathrm{CD}^{+} \mathrm{T}$ cells, counteracting the efficacy of anti-PD-1 checkpoint blockade. Additionally, similar to the development of bispecific anti-CD19xFc $\gamma$ RIIB antibodies to modulate $B$ cell activation $(29,30)$, there may be a therapeutic role for bispecific anti-CD8xFc $\gamma$ RIIB antibodies to modulate $\mathrm{T}$ cell activation in melanoma treatment. In an era where immunotherapeutic agents now provide durable efficacy and improved outcomes for patients with metastatic melanoma, a thorough understanding of the Fc $\gamma$ RIIB pathway and its T cell-autonomous inhibitory role in melanoma-specific immunity will contribute to further improvement in pharmacologic strategies and patient outcomes.

\section{Methods}

Mice. B6-Ly5.1/Cr (H2-K $\left.\mathrm{K}^{\mathrm{b}}, \mathrm{CD} 45.1\right)$ and $\mathrm{C} 57 \mathrm{BL} / 6 \mathrm{~N}\left(\mathrm{H} 2-\mathrm{K}^{\mathrm{b}}, \mathrm{CD} 45.2\right)$ mice were obtained from the National Cancer Institute (Charles River, Frederick, Maryland, USA). OT-I (31) and OT-II (32) transgenic mice (C57BL/6 background) purchased from Taconic Farms were bred to C57BL/6 Thy $1.1^{+}$congenic animals at Emory University. EM:06078 Fcgr2b Fcgr2bB6null B6(Cg)-Fcgr2btm12Sjv/Cnbc (or Fcgr2b ${ }^{-1-}$ ) 
mice (33) were purchased from the European Mutant Mouse Archive and provided by Academisch Siekenhuis Leiden/Leiden University Medical Center from JS Verbeek (Leiden University Medical Center, Leiden, the Netherlands). B6 embryonic stem cells were used to generate these mice. $F c g r 2 b^{-1}$ mice were bred to OT-I transgenic mice at Emory University.

Adoptive cell transfer. To monitor antigen-specific $\mathrm{CD}^{+} \mathrm{T}$ cell responses, we adoptively transferred OVA-specific transgenic T cells into naive prior to inoculation with B16 melanoma expressing OVA. For the adoptive transfer of tumor-specific $\mathrm{CD}^{+} \mathrm{T}$ cells, spleens and mesenteric lymph nodes from $\mathrm{CD} 45.2^{+} \mathrm{Thy} 1.2^{+}$ $\mathrm{Fcgr}_{2 b^{-/-}}$OT-I mice or CD45.2+Thy1.1+ WT OT-I mice were processed into single-cell suspensions. Cells were counted using a Nexcelom Cellometer Auto T4 (Nexcelom Bioscience) and stained with CD8-BV785,

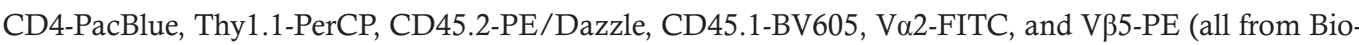
Legend). The frequency of OT-I and OT-II cells was determined via V $\alpha 2$ and V $\beta 5$ TCR coexpression. Cells were then resuspended in $1 \times$ PBS and $1 \times 10^{6}$ OT-I and $1 \times 10^{6}$ OT-II cells were transferred intravenously into naive congenic CD45.1 ${ }^{+}$B6-Ly5.1/Cr hosts 24 hours prior to tumor inoculation.

Cancer cell line and inoculation. B16 melanoma cells engineered to express the OVA epitope (B16-OVA) were provided by Yang-Xin Fu (University of Texas Southwestern, Dallas, Texas, USA) (34). For all experiments, B16-OVA cells were harvested using trypsin, washed in PBS, and counted, and $10^{6}$ cells were inoculated into the subcutaneous tissue of the right flank. Tumor growth was monitored by daily visual inspection. Tumor volume was calculated using caliper measurement of height, width, and depth.

Flow cytometric analyses. Spleen, dLN (right inguinal), and tumor cells from mice were processed to cell suspensions and stained according to manufacturer's instructions with biotinylated-CD16/32 (clone 2.4G2, BD Biosciences) or a biotinylated isotype control (IgG2bk, BD Biosciences), CD8-BV786 (BioLegend), CD4PacBlue (BioLegend), CD19-BV510 (BioLegend), CD44-APC/Cy7 (BioLegend), CD62L-PE/Cy7 (BioLegend), Thy1.1-PerCP (BioLegend), CD45.1-BV605 (BioLegend), CD45.2-PE/Dazzle (BioLegend), 2B4-PE (BioLegend), PD-1-PE/Dazzle (BioLegend), and APC Streptavidin (BD Biosciences). FcyRIIB staining on human PBMCs was performed using anti-human CD32 mAb (clone FLI8.26, BD Biosciences). PBMCs were also stained with CD14-BV510 (clone M 9 P9), CD19-BV510 (clone SJ25C1), CD3-BUV737 (clone UCHT1), CD4-BUV805 (clone SK3), CD8-BUV496 (clone RPA-T8), and CD45RA-Alexa Fluor 700 (clone HI100; all purchased from BD Biosciences) and CCR7-PE/Dazzle (clone G043H7, purchased from BioLegend). For intracellular marker and cytokine staining, cells were incubated for 4 hours at $37^{\circ} \mathrm{C}$ in the presence of $30 \mathrm{ng} /$ $\mathrm{mL}$ PMA, $400 \mathrm{ng} / \mathrm{mL}$ Ionomycin, and $10 \mu \mathrm{g} / \mathrm{mL}$ GolgiPlug (BD Biosciences). In some experiments, cells were activated with $30 \mathrm{nM}$ OVA SIINFEKL peptide (GenScript) and $10 \mu \mathrm{g} / \mathrm{mL}$ GolgiPlug (BD Biosciences). After 4 hours, cells were processed using the BD Cytofix/Cytoperm Kit (BD Biosciences) according to manufacturer's instructions and stained with PE/Cy7 anti-human TNF- $\alpha$ Antibody and Alexa Fluor 700 anti-human IFN- $\gamma$ Antibody (BioLegend). Absolute cell numbers were determined by CountBright Absolute Counting Beads according to the manufacturer's instructions (Thermo Fisher). Flow cytometric analysis was performed on an LSRII flow cytometer (BD Biosciences). Data were analyzed using FlowJo 9.9.4 software (Tree Star).

Human subjects. Whole blood was acquired from anonymous healthy donors $(n=6)$ and treatment-naive patients with stage IV melanoma $(n=6)$ at Emory University Hospital/Winship Cancer Center. There was no significant difference in ethnicity or sex between healthy subjects and patients with melanoma. Four of six healthy donors identified as Asian and two of six identified as White. Four of five were male (age range 25-63 years). Five of six patients with melanoma identified as White, and one of six identified as African American. Four of six were male (age range 39-78 years).

Statistics. All assays were compared using a Mann-Whitney $U$ nonparametric test when comparing 2 groups, 1-way ANOVA (with Tukey's correction for multiple comparisons) when comparing 1 variable across multiple groups, or a 2-way ANOVA (with Sidak's correction for multiple comparisons) when comparing 2 variables across multiple groups. Statistical analyses were conducted using GraphPad Prism 7. In all figures, data are represented as the mean \pm SEM. $P$ values of less than 0.05 were considered significant.

Study approval. Animal studies were approved by the Institutional Animal Care and Use Committee of Emory University (protocol no. PROTO201700558). This study was carried out in strict accordance with the recommendations in the Guide for the Care and Use of Laboratory Animals (National Academies Press, 2011). All animals were maintained in accordance with Emory University Institutional Animal Care and Use Committee guidelines. All animals were housed in specific pathogen-free animal facilities at Emory University. Use of samples from human subjects was approved by Emory University's Institutional Review Board (protocol no. 00046593) and informed consent was acquired. 


\section{Author contributions}

CRF designed and performed experiments, acquired and analyzed the data, and wrote the manuscript. ABM designed and performed experiments, analyzed data, and edited the manuscript. CRF and ABM contributed equally to this work. MT and KBB performed experiments, analyzed data, and edited the manuscript. SP analyzed data. MCL and RK recruited patients with melanoma and edited the manuscript. MLF conceived of the study, obtained funding, designed experiments, analyzed the data, and wrote the manuscript.

\section{Acknowledgments}

This work was supported by NIAID R01 AI073707 (to MLF) and by a Melanoma Innovation Fund Award from the Winship Cancer Institute of Emory University (to MLF). CRF was supported by a Surgical Oncology Melanoma Research Fellowship and Elkin Fellowship Award from the Winship Cancer Institute of Emory University, and ABM was supported by NIH T32 AI070081. The authors would like to acknowledge Keith Delman for helpful discussions and Jennifer Robertson for flow cytometry expertise.

Address correspondence to: Mandy L. Ford, Emory University, 101 Woodruff Circle Suite 5105, Atlanta, Georgia 30322, USA. Phone: 404.727.2900; Email: mandy.ford@emory.edu.

1. Siegel RL, et al. Cancer statistics, 2018. CA Cancer J Clin. 2018;68(1):7-30.

2. Force J, Salama AK. First-line treatment of metastatic melanoma: role of nivolumab. Immunotargets Ther. 2017;6:1-10.

3. Pardoll DM. The blockade of immune checkpoints in cancer immunotherapy. Nat Rev Cancer. 2012;12(4):252-264.

4. Copur MS, Obermiller A. Ipilimumab plus dacarbazine in melanoma. N Engl J Med. 2011;365(13):1256-1257.

5. Herzberg B, Fisher DE. Metastatic melanoma and immunotherapy. Clin Immunol. 2016;172:105-110.

6. Nimmerjahn F, Ravetch JV. Fcgamma receptors as regulators of immune responses. Nat Rev Immunol. 2008;8(1):34-47.

7. Espeli M, et al. FcgammaRIIB and autoimmunity. Immunol Rev. 2016;269(1):194-211.

8. Smith KG, Clatworthy MR. FcgammaRIIB in autoimmunity and infection: evolutionary and therapeutic implications. Nat Rev Immunol. 2010;10(5):328-343.

9. Nakamura A, et al. Fcgamma receptor IIB-deficient mice develop Goodpasture's syndrome upon immunization with type IV collagen: a novel murine model for autoimmune glomerular basement membrane disease. J Exp Med. 2000;191(5):899-906.

10. Yuasa T, et al. Deletion of fcgamma receptor IIB renders H-2(b) mice susceptible to collagen-induced arthritis. $J$ Exp Med. 1999;189(1):187-194.

11. Lim SH, et al. Fc gamma receptor IIb on target B cells promotes rituximab internalization and reduces clinical efficacy. Blood. 2011;118(9):2530-2540.

12. Roghanian A, et al. Antagonistic human Fc $\gamma$ RIB (CD32B) antibodies have anti-tumor activity and overcome resistance to antibody therapy in vivo. Cancer Cell. 2015;27(4):473-488.

13. Roghanian A, et al. Resistance is futile: targeting the inhibitory FcyRIIB (CD32B) to maximize immunotherapy. Oncoimmunology. 2016;5(2):1069939.

14. Roghanian A, et al. New revelations from an old receptor: Immunoregulatory functions of the inhibitory Fc gamma receptor, FcgammaRIIB (CD32B) [published online February 6, 2018]. J Leukoc Biol. https://doi.org/10.1002/JLB.2MIR0917-354R.

15. White AL, et al. Interaction with Fc $\gamma$ RIIB is critical for the agonistic activity of anti-CD40 monoclonal antibody. J Immunol. 2011;187(4):1754-1763.

16. Li F, Ravetch JV. Inhibitory Fc $\gamma$ receptor engagement drives adjuvant and anti-tumor activities of agonistic CD40 antibodies. Science. 2011;333(6045):1030-1034.

17. Clynes RA, et al. Inhibitory Fc receptors modulate in vivo cytotoxicity against tumor targets. Nat Med. 2000;6(4):443-446.

18. Yoshida TO, Andersson B. Evidence for a receptor recognizing antigen complexed immunoglobulin on the surface of activated mouse thymus lymphocytes. Scand J Immunol. 1972;1(4):401-408.

19. Anderson CL, Gray HM. Receptors for aggregated IgG on mouse lymphocytes: their presence on thymocytes, thymus-derived, and bone marrow-derived lymphocytes. J Exp Med. 1974;139(5):1175-1188.

20. Stout RD, Herzenberg LA. The Fc receptor on thymus-derived lymphocytes. I. detection of a subpopulation of murine T lymphocytes bearing the Fc receptor. J Exp Med. 1975;142(3):611-621.

21. Wirth TC, et al. Repetitive antigen stimulation induces stepwise transcriptome diversification but preserves a core signature of memory CD8(+) T cell differentiation. Immunity. 2010;33(1):128-140.

22. Alfei F, et al. TOX reinforces the phenotype and longevity of exhausted T cells in chronic viral infection. Nature. 2019;571(7764):265-269.

23. Starbeck-Miller GR, et al. Cutting edge: expression of Fc $\gamma$ RIIB tempers memory CD8 T cell function in vivo. J Immunol. 2014;192(1):35-39.

24. Morris AB, et al. Signaling through the inhibitory $\mathrm{Fc}_{\mathrm{c}}$ receptor $\mathrm{Fc} \gamma \mathrm{RIIB}$ induces $\mathrm{CD} 8^{+} \mathrm{T}$ cell apoptosis to limit $\mathrm{T}$ cell immunity. Immunity. 2020;52(1):136-150.

25. Dowlatshahi M, et al. Tumor-specific T cells in human Merkel cell carcinomas: a possible role for Tregs and T-cell exhaustion in reducing T-cell responses. J Invest Dermatol. 2013;133(7):1879-1889.

26. Thommen DS, et al. A transcriptionally and functionally distinct $\mathrm{PD}-1^{+} \mathrm{CD} 8^{+} \mathrm{T}$ cell pool with predictive potential in non-small-cell lung cancer treated with PD-1 blockade. Nat Med. 2018;24(7):994-1004.

27. Cassard L, et al. Selective expression of inhibitory Fcgamma receptor by metastatic melanoma impairs tumor susceptibility 
to IgG-dependent cellular response. Int J Cancer. 2008;123(12):2832-2839.

28. Catakovic K, et al. T cell exhaustion: from pathophysiological basics to tumor immunotherapy. Cell Commun Signal. 2017;15(1):1.

29. Karnell JL, et al. CD19 and CD32b differentially regulate human B cell responsiveness. J Immunol. 2014;192(4):1480-1490.

30. Chu SY, et al. Inhibition of B cell receptor-mediated activation of primary human B cells by coengagement of CD19 and

FcgammaRIIb with Fc-engineered antibodies. Mol Immunol. 2008;45(15):3926-3933.

31. Hogquist KA, et al. T cell receptor antagonist peptides induce positive selection. Cell. 1994;76(1):17-27.

32. Barnden MJ, et al. Defective TCR expression in transgenic mice constructed using cDNA-based alpha- and beta-chain genes under the control of heterologous regulatory elements. Immunol Cell Biol. 1998;76(1):34-40.

33. Boross $\mathrm{P}$, et al. The inhibiting Fc receptor for IgG, FcyRIIB, is a modifier of autoimmune susceptibility. J Immunol. 2011;187(3):1304-1313.

34. Brown DM, et al. Tumours can act as adjuvants for humoral immunity. Immunology. 2001;102(4):486-497. 